\title{
Vibration and functional tests on a new designed battery pack of a micro-satellite
}

\author{
Moharam Ghahramani Darvish*
}

Semnan University, Semnan, Iran

\begin{tabular}{l}
\hline A R T I C L EI N F O \\
\hline Article history: \\
Received 22 November, 2017 \\
Accepted 1 January 2018 \\
Available online \\
2 January 2018 \\
\hline Keywords: \\
Battery pack design \\
Satellite, vibration test \\
ECSS standard \\
Experimental study
\end{tabular}

\section{Introduction}

Cordless products or devices which use rechargeable batteries are widely used in many applications. The rechargeable batteries are utilized in numerous from computer products and/or housewares to power tools. Nickel-cadmium, nickel-metal-hydride battery and/or lithium-ion cells are among different types which may be used in these devices. Since these devices use a plurality of the battery cells, they may be ordinarily packaged as the battery packs. These battery packs can be coupled with the cordless devices so as to secure the pack on the device. The battery pack may be removed from the cordless device and charged in a battery charger or on the cordless device itself. Satellites are also among the manmade machines that work with the power of chargeable batteries while batteries are themselves charged by solar cells mounted on the satellite body. Various payloads and mission durations make it impossible to use a single spacecraft "bus" to carry different payloads, since a small bus cannot carry sufficient amount of propellant in addition to its payload for an extremely long mission. On the other hand, a very large bus might be too expensive for a small payload within a shortduration mission. The battery cells are temperature sensitive and also produce heat. In many spacecraft

\footnotetext{
* Corresponding author.

E-mail addresses: M_ghahremani@semnan.ac.ir (M. Ghahramani Darvish) 
designs the battery cells are isolated within the spacecraft structure for better temperature control. Different numbers of the cells are required for different missions so that a detailed thermal analysis seems necessary. Consequently, the satellite fabrication industry incorporates extremely expensive crafting and customization, and design of structures using the existing components and parts may happen to meet the requirements of the component design. The resulting spacecraft must be individually qualified, because each one is significantly different from another one. The individual manmade and space qualification tends to increase both spacecraft costs and procurement time.

Generally, the spacecraft lifetime is related to the lifetime of its power source. In practice a battery pack is subjected to both mechanical and thermal loads and hence the battery pack should be suitably designed such that is able to protect the cells against environmental loads. The review of literature shows that the vast majority of battery packs in the shape of rectangular packs and matrix type arrangement (Pedersen et al., 1998; Clark et al., 1998; Pearson et al., 2004, 2005, 2006; Koeck \& Radola, 2011; Kim et al., 2009; Bolandi et al., 2016). This layout for battery cells has some shortcomings like non-uniform distribution of thermal loads around the cells (Pesaran et al., 1997) hence some other researchers have proposed other cell layouts inside the battery pack (e.g. radial type for instance) (Bauer 1998). In addition, the compactness of the packs reduces not only the volume occupied by the packs but also the total weight for large power applications (Kizilel et al., 2008). Therefore, in this paper a new circular type battery pack design is utilized for a typical microsatellite by modification in material selection and arrangement of the battery cells, in order to overcome the launch process problems and improve the thermal resistance of the battery cells in use.

\section{Battery pack Design}

Some design parameters should be considered during battery pack design. The first point is the short contact of the battery cells that is significantly important. For this purpose, one must put the battery cells inside an insulated structure. Then, a material is needed with minimum outgassing to withstand against vacuum conditions out of the atmosphere. A PTFE (poly tetra fluoro ethylene) part is thus selected for the internal part of pack structure.

Taking into account the mechanism of heat transfer outside the earth atmosphere which can be done by either radiation or conduction, the arrangement of the batteries inside the pack must be such that all the battery cells are located in the same position in terms of the heat transfer. Thus a circular arrangement was proposed in this research for design of satellite battery pack as shown in Fig. 1

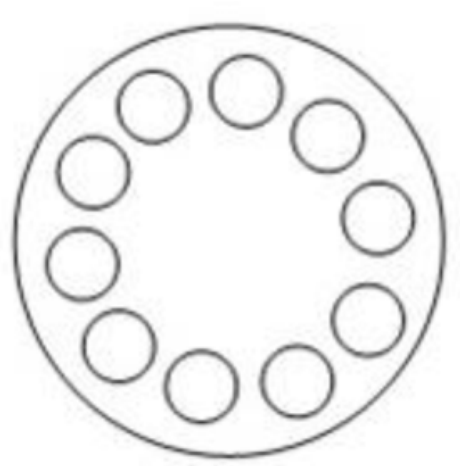

Fig. 1. A schematic view of designed battery pack in a circular layout

A circular layout provides more uniform distribution of heat generation inside the battery pack and can also prevent the mechanical damage of cells more efficiently in comparison with the matrix type 
layout for battery cells. The structure of pack should be designed in a way such that keep safe the battery cells against mechanical loads in the launch conditions. Hence as shown in Fig.2a metallic structure is utilized and used for surrounding the cells and their internal protection. The exploded view of designed battery pack that is consists of four main assembly parts have been presented in Fig.2.

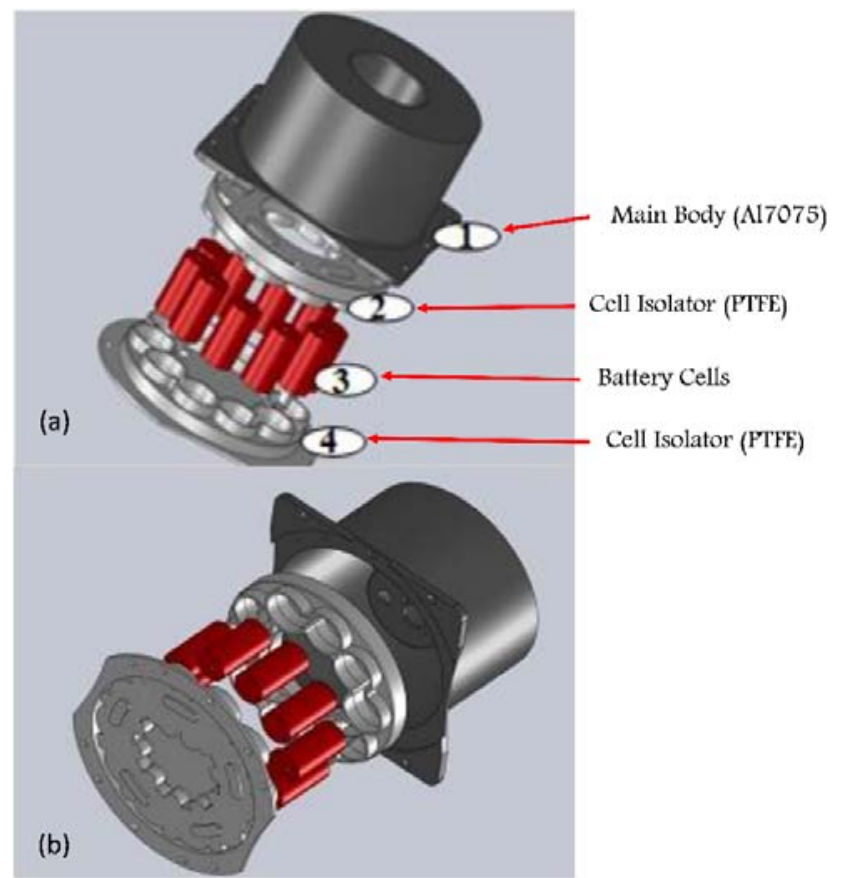

Fig. 2. Exploded view of battery pack made of four parts.

The main structure of the battery pack that holds the other parts together is made from a 7075 aluminum alloy and formed for locating the electrical connectors on the battery pack and the pack on the spacecraft body. However to use the designed battery pack in real satellite structures it is necessary to pass the mechanical tests, applied during lunch. Indeed, the pack should provide proper function both during and after the mechanical tests. For this purpose, the battery pack was tested in accordance with the European cooperation for space standardizing (ECSS), including sinusoidal test and random vibration test according to ECSS-E-10-03A (2003) and ECSS-Q-70-02A (2003). A brief description of mechanical tests in accordance with the ECSS is illustrated in the next section.

\section{Mechanical tests}

\subsection{Sinusoidal Test}

In a typical sinusoidal test, the satellite is examined using a sinusoidal excitement which sweeps through a frequency band or remains constant at a certain frequency band. The sweep rate for a sinusoidal motion expressed as logarithmic scale often characterized by octave per minute. A unit change in the octaves means twice or half the frequency, while the volatility is increased or reduced, respectively. Generally speaking, the domain of the sinusoidal sweepers is a function of the frequency and identified using acceleration, velocity, displacement or a combination of these parameters. The sinusoidal test is useful to determine the effects of the responded conditions and for simulation of the environments having narrow-band frequency components. This test is usually of secondary importance as compared to the random testing, while a broadband frequency spectrum is needed for the excitement. The purpose of the sinusoidal test is to ensure the ability of the components to tolerate against the lowfrequency excitement applied from the launcher side to the satellite structure. According to the ECSS standard, the sweeping rate is equal to 2 octaves and this test is carried out in for all 3 axes for 2 minutes per each one. 


\subsection{Random Vibration Test}

A random vibration test for the satellite is used to excite all the frequencies in the bandwidth, which is typically between 20 and $2000 \mathrm{~Hz}$. The energy is controlled in a specified level at each frequency. The random vibration test is considered as one of the main examinations which provide the best simulation of the real environment. As there is not a large number of the natural frequencies in a bandwidth, this is not applicable to excite all the frequencies in the bandwidth. Therefore, implementation of the random testing of bandwidth a line (Filter bandwidth) depends on the capabilities of the control system and also the skills of the test operator. The levels of amplitudes are determined normally using the unit of $\mathrm{g} / \mathrm{Hz}$, where g denotes the acceleration which the satellite body takes under the vibration. The values of $\mathrm{Hz}$ are within the limit range of the filter bandwidth. The random vibration testing is implemented to ensure that the component withstands against the random excitation applied from the launcher. The random vibration test is done in all the three axes and in the frequency range of $5-2000 \mathrm{~Hz}$.

\section{Experimental test results performed on Battery pack}

Before beginning of the environmental mechanical tests, functional testing is performed on the battery pack to check its electrical performance. Then, according to Table 1 , the vibration testing is performed to address the natural frequencies in the frequency range of 5-2000 Hz. Based on the ECSS standard, the sinusoidal testing is done for the units with a mass under $50 \mathrm{~kg}$ at $100 \mathrm{~Hz}$ (See Table (2)). Fig. 3 shows the experimental set up utilized for testing the battery pack on a shaker. In order to record the test data a three-axis sensor was also mounted on the battery pack as shown in Fig. 4. The obtained sinusoidal vibration test data for the tested pack has also been presented in Fig. 5.

Table 1. Determination of natural frequencies

\begin{tabular}{lll}
\hline frequency & level & Sweep rate \\
$(5-2000) \mathrm{Hz}$ & $0.5 \mathrm{~g}$ & 2 octave per minute \\
\hline
\end{tabular}

Table 2. Sinusoidal test frequencies according to ECSS standard in satellite component tests

\begin{tabular}{lll}
\hline frequency & level & Sweep rate \\
$(5-21) \mathrm{Hz}$ & $11 \mathrm{~mm}(0$-peak $)$ & No notching \\
$(21-60) \mathrm{Hz}$ & $20 \mathrm{~g}(0$-peak) & \\
$(60-100) \mathrm{Hz}$ & $6 \mathrm{~g}(0$-peak $)$ & \\
\hline
\end{tabular}

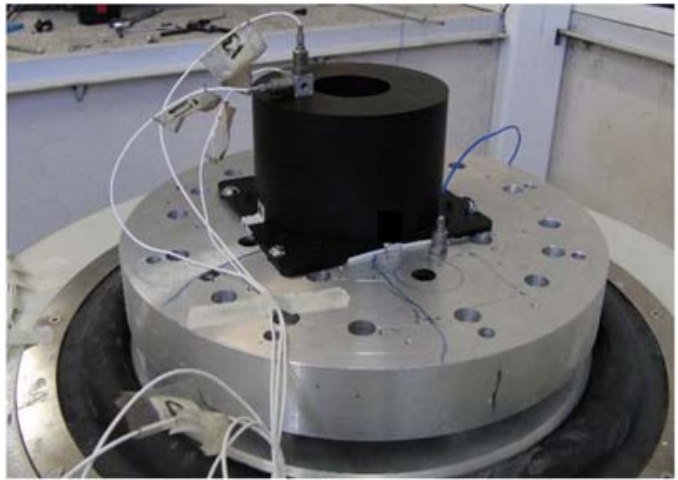

Fig. 3. Satellite battery pack during vibration test on a shaker

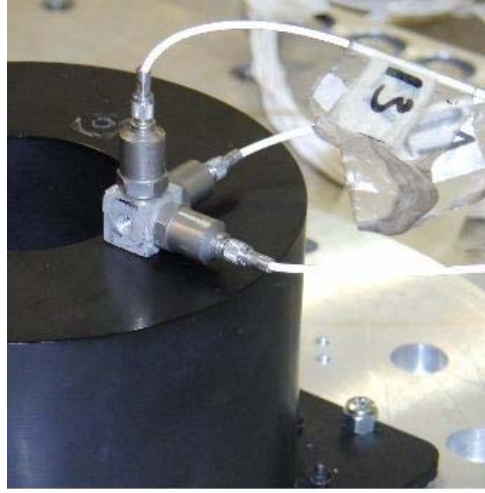

Fig. 4. Three-axis sensors mounted on a battery pack during vibration test 


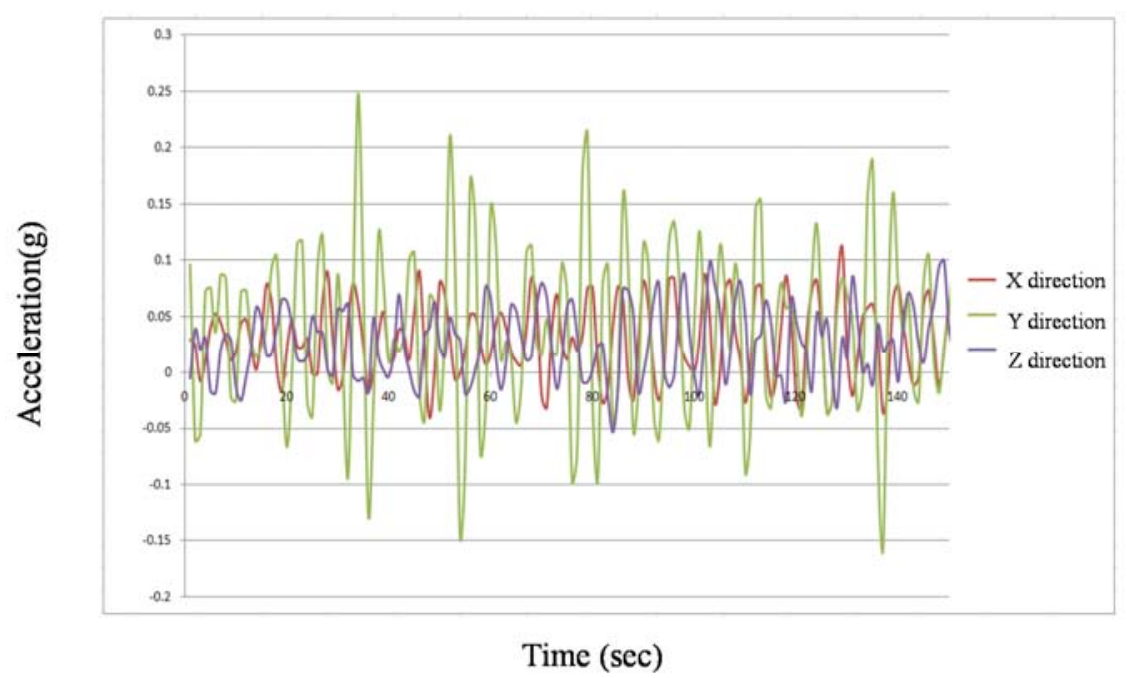

Fig. 5. Results of sinusoidal vibration test of a battery pack

After performing the sinusoidal test, the random vibration test was done on the battery pack, according to Table 3, in order to detect the natural frequency in the range of 5 - $2000 \mathrm{~Hz}$. According to the ECSS standard, the random vibration testing is performed for two minutes, followed by the functional test. The results of the random vibration testing which are recorded using the three-axis sensors are depicted in Fig. 6.

Table 3. Level of random testing

\begin{tabular}{lll}
\hline Frequency & Level & Sweep rate \\
$(5-2000) \mathrm{Hz}$ & $0.5 \mathrm{~g}$ & 2 octave per minute \\
\hline
\end{tabular}

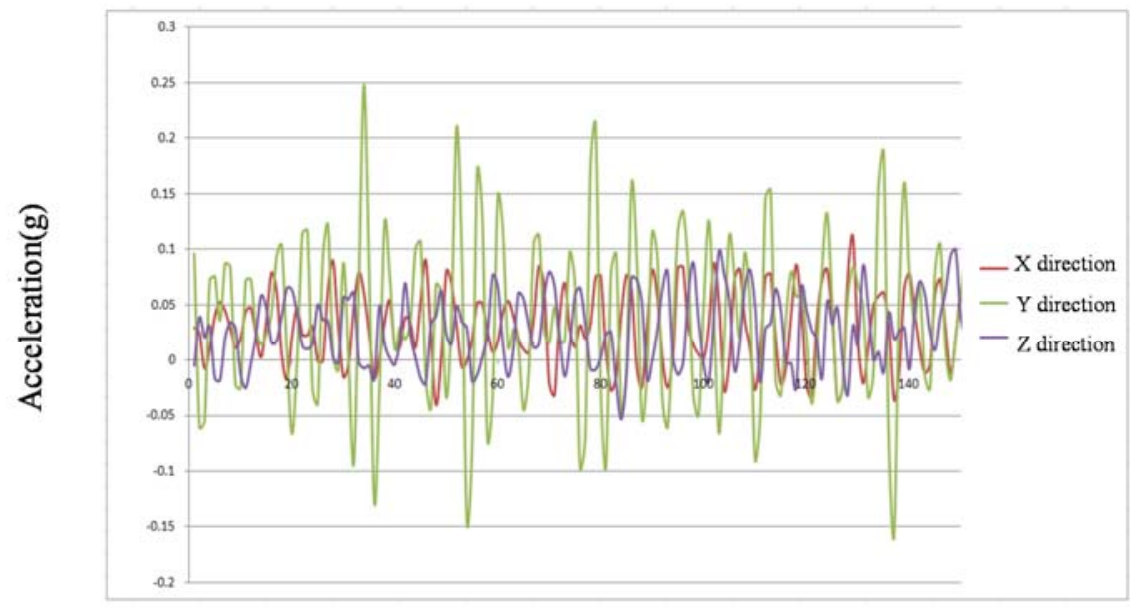

Time (sec)

Fig. 6. Results of random vibration test on battery pack

\section{Discussion and Conclusion}

In order to verify the design and manufacturing process of the investigated battery pack, a functional test should be carried out on the pack. The performance of battery cells after the vibration tests should be in a desirable range in accordance with the ECSS standard. As the main acceptance criterion for the battery device, the charging performance of cell after and before vibration and dynamic tests was measured. As shown in Fig. 7 a good agreement is seen between the result of battery charging 
curve before and after the mechanical testing. This observation demonstrated that the designed pack can protect very well the cells against mechanical loads induced during the lunch process. Therefore, the new designed battery pack can be used successfully for real space mission and for wide range of satellites due to its advantages like more uniform distribution of thermal effects generated inside the pack and ability of passing the mechanical tests based on the ECSS standard.

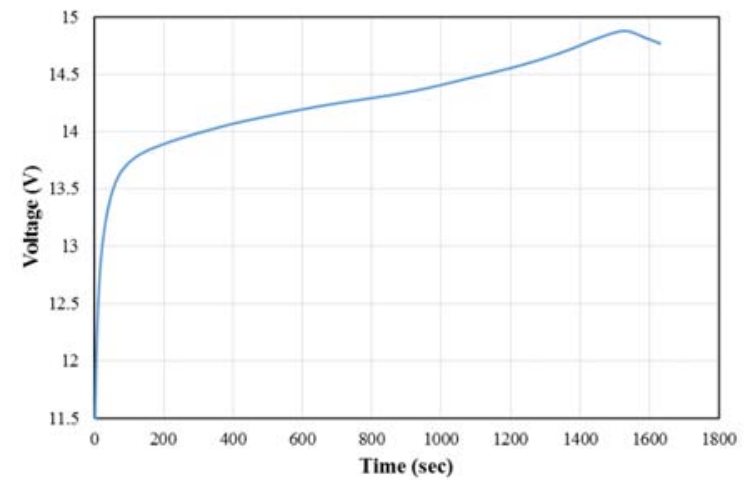

(a)

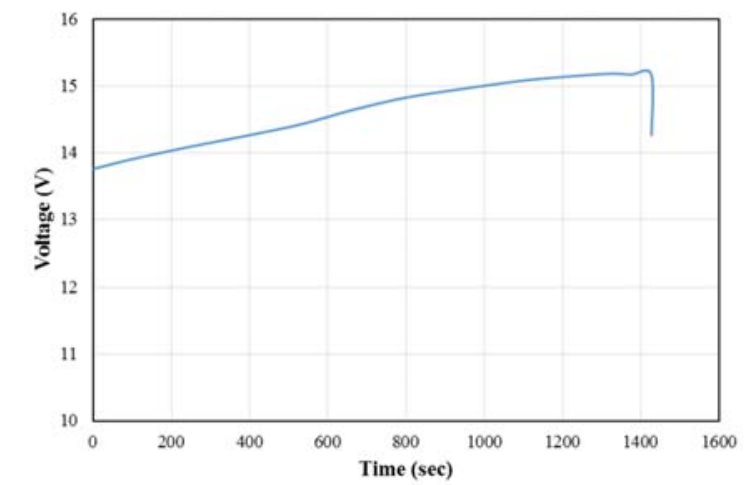

(b)

Fig. 7. Charging curve of battery (a) before and (b) after vibration test

\section{References}

Bauer, P. (1968). Batteries for space power systems; national aeronautics and space administration Washington, D.C.

Bolandi, H., Darvish, M. G., \& Hasanian, M. (2016). Design Manufacture and Environmental Tests of Battery Pack for Spacecraft Freights. International Journal of Advanced Design and Manufacturing Technology, 9(3).

Koeck, C., \& Radola, D. (2011). AstroSAT 100: Microsatellite solution for high resolution remote sensing systems. Proceedings of IAC 2011 (62nd International Astronautical Congress), Cape Town, South Africa, Oct. 3-7, 2011, paper: IAC-11-B4.4.4.

Clark, C. S., Hill, A. D., \& Day, M. (1998). Commercial nickel cadmium batteries for space use: a proven alternative for LEO satellite power storage. In Proceedings of the Fifth European Space Power Conference (ESPC) (Vol. 416, p. 715).

Kim, B., Al Marri, S., \& Hamzah, N. (2009). SI-200 Mini-Satellite Platform for Earth Observation Missions. In 23rd Annual AIAA/USU Conference on Small Satellites, Logan UT.

Kizilel, R., Lateef, A., Sabbah, R., Farid, M. M., Selman, J. R., \& Al-Hallaj, S. (2008). Passive control of temperature excursion and uniformity in high-energy Li-ion battery packs at high current and ambient temperature. Journal of Power Sources, 183(1), 370-375.

Pearson, C., Bennetti, A., \& Spurrett, R. (2006) Advances In Battery Technology Relevant For Planetary Probes.

Pearson, C., Thwaite, C., \& Russel, N. (2004). The Use of Small Cell Lithium-Ion Batteries for Small Satellite Applications.

Pearson, C., Thwaite, C., \& Russel, N. (2005, April). Small cell lithium-ion batteries: the responsive solution for space energy storage. In AIAA International Conference on Responsive Space (Vol. 3).

Pedersen, F. H., Balard, C., Barde, H., \& Weinberg, S. (1998). A Modular Battery Power Pack for Regulated Bus Applications. In Proceedings of the Fifth European Space Power Conference (ESPC) (Vol. 416, p. 85).

Pesaran, A. A., Vlahinos, A., \& Burch, S. D. (1997). Thermal performance of EV and HEV battery modules and packs. National Renewable Energy Laboratory.

Secretariat, E. C. S. S. (2003), space engineering: Testing ECSS-E-10-03A

Secretariat, E. C. S. S. (2003). Thermal vacuum outgassing test for the screening of space materials. ECSS-Q70-02A.

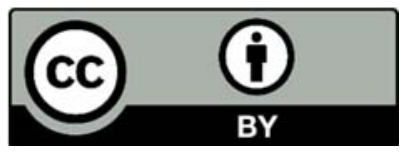

(C) 2018 by the authors; licensee Growing Science, Canada. This is an open access article distributed under the terms and conditions of the Creative Commons Attribution (CC-BY) license (http://creativecommons.org/licenses/by/4.0/). 